\title{
Using ICT as a Value Adding Tool in South African SMEs
}

\author{
Reza Ismail, Robyne Jeffery and Jean-Paul Van Belle \\ Department of Information Systems, University of Cape Town, South Africa
}

\begin{abstract}
This article investigates how Information and Communication Technology (ICT) has been used to add value to Small and Medium Enterprises (SMEs) in South Africa, particularly in the retail, production and service provision sectors. This empirical study had three objectives. The first objective was to find out which ICTs South African SMEs are currently using. The second goal was to investigate what SME owners perceived and what value ICTs added to their operations. Finally, the various barriers which SMEs face when adopting ICTs were looked at. It was found that ICT does indeed add value to SMEs, the use of ICT differs between different sectors, and South African SMEs encounter a number of critical barriers in the process of adopting ICT.
\end{abstract}

Keywords: ICTs, Small and Medium-sized Enterprises, Value, South Africa, Barriers to ICT Adoption.

\section{Introduction}

Information and Communication Technologies (ICTs) have the potential to add substantial value to the operations and the competitive position of Small and Medium-sized Enterprises (SMEs). However, SMEs are often reluctant to embracing technological change and rather adopt more traditional approaches and means of conducting business and operations. In order to compete on a much wider scale, the many benefits of ICT needs to be taken into consideration and awareness thereof needs to be raised.

This article investigates specifically at the role that Information and Communication (ICT) plays within Small to Medium Enterprises (SMEs) in South Africa. The objectives of this study were threefold. Firstly, it aimed to find out which ICTs SMEs are currently using in South Africa. Secondly, to delve into the perceived value added to SMEs through ICT adoption and thirdly, to uncover the various barriers SMEs face when adopting ICTs. The research collected data from SMEs in three main sectors in South Africa by means of a questionnaire. The three sectors focused on were the retail, production and service provision sectors in South Africa.

There has been limited research conducted on the use of ICT as a value adding tool amongst SMEs in South Africa. The extent of use of different ICTS in SMEs, the stumbling blocks to actual adoption of ICT and the perceptions of SME owners with regards to adoption and use have not been fully explored as yet. It remains to be seen, whether or not, ICT adds any value or brings any direct benefit to SMEs in South Africa. Hence, this study will be of immediate support to the growing SME sector in South Africa's economy and at the same time, will add to the current literature of ICT and SMEs in South Africa.

\section{Importance of Small Medium Enterprise (SME) in South Africa}

SMEs are usually defined according to the number of employees within the

Copyright (C) 2011 Reza Ismail, Robyne Jeffery and Jean-Paul Van Belle. This is an open access article distributed under the Creative Commons Attribution License unported 3.0, which permits unrestricted use, distribution, and reproduction in any medium, provided that original work is properly cited. Contact author: Jean-Paul Van Belle e-maill: Jean-Paul.VanBelle@uct.ac.za 
enterprise, or on the value of assets. Hallberg (2000) classifies an enterprise with 250 employees as an SME (the definition also adopted in this article), whereas Southern and Tilley (2000) stipulate 150 or fewer employees. Even though there is not one exact definition of the term Small to Medium Enterprise, there are however a number of organisational characteristics which can be used to distinguish these types of businesses from large ones. Jentzsch and Miniotas (1999) characterize SMEs as independently owned and operated enterprises, where most of the operating capital is provided by the owner and the principal management and decision making is done by the owners.

In South Africa, SMEs are seen not only as a strong engine of economic growth and productivity, but also, as a means of distributing income amongst its employees and their affiliates. The SME sector is seen as the most prospective part of South Africa's economy (Al Berry et al., 2002). The SME economy sector increases the average productivity of labour in the country by employing the average unemployed low-skilled labour force who is actively seeking employment (Bacon \& Hoque, 2005; Locke, 2004).

\section{Benefits of ICTs for SMEs}

Selwyn (2002) states that Information and Communication Technology is a term including a wide range of technological applications; digital broadcast technologies; telecommunications technologies as well as electronic information resources. ICT therefore, encompasses a range of technologies, information and resources (Selwyn, 2002).

Information and Communication Technologies are seen as a competitive tool for enterprises (Modimogale and Kroeze, 2009) and, if implemented and used correctly, can bring with it many benefits for enterprises. These benefits include permitting collaboration between the adopting business and other businesses and making the business faster through more effective processes, as well as giving businesses the ability to retrieve, store and process information much more efficiently (in terms of both cost and effort) (Taylor, 2004).

Information technology has shifted from being a resource barely employed in businesses to one of extreme importance, which businesses invest in to gain competitive advantage (Carr, 2004). The main driver behind this shift or transformation is due to the assumption that information technology's increase in ubiquity and potency has increased its strategic value (Carr, 2004).

Competitive advantage refers to the situation an organisation finds itself in when it implements a value creating strategy which is not being simultaneously implemented by any of its competitors (Hoffman, 2000). This competitive advantage becomes a sustainable one if none of the current or potential competitors in the industry are able to duplicate the benefits of the strategy implemented. This allows the firm to be the only organisation in the respective industry to have this 'edge' and reap the benefits thereof, whilst competitors are still using "older" means of doing business (Hoffman, 2000). According to Porter, businesses can gain a competitive advantage in their respective industry in two main ways, namely cost advantage, or differentiation advantage (Porter, 2001). Both sources of advantage can be gained by businesses through strategic positioning with the use of the internet (Porter, 2001).

The problem which arises with organisations gaining a competitive advantage is that it tends to be more of a once off occurrence than something sustained. Peppard and Ward (2004) qualify this by stating that recent surveys on competitive advantage have deemed it both "temporary and non-lasting". They also see the problem to be that, although some ICT initiatives taken do reap rewards for the business that implements it, many of these initiatives can be easily replicated by other competitors in the industry, thus causing any competitive advantage gained to be minimised quickly.

However, the insight to harness some ICT initiative's usefulness may not necessarily 
become ubiquitous, and that is where the opportunity for strategic advantage within Information Technology lies. In order to extract real value from IT, business process re-engineering and business process innovation is required (Carr, 2004). First mover businesses, that is, those that tend to act on the possibilities that IT brings before rivals do, will continue to differentiate themselves in the light of their respective industry competitors and thus, reap the economic rewards of the IT investment.

From an operational perspective, introducing ICTs into the value chain changes the way it operates and has a direct influence on the links between the various functional units of an organisation. This relationship between ICT and an organisation's value chain with IT having the power to refine it and the linkages within it, shows that IT plays a pivotal role in creating value for an organisation (Porter and Millar, 1985).

From a competitive perspective, Information Technology can change the rules of competition in various ways. Porter and Millar (1985) suggested that there are five main competitive forces within an industry structure which determine industry profitability for an organisation. IT can affect each of these forces as follows:

- Power of Buyers: IT makes information more widely available to larger target markets, thus giving buyers' greater purchasing power through better and faster information.

- Power of Suppliers: IT allows suppliers to gauge supply and demand for their products much better, as they get better information on their inputs.

- Threat of New Entrants: IT raises the barriers to entry in an industry.

- Threats of substitutes: Physical products are replaced by technology driven substitutes.

- Rivalry amongst existing competitors: Organisations need to keep up to speed with new technologies in order to avoid being the last to implement a certain technology and fall behind competitors. Process improvements using IT need to be made constantly to ensure competitive advantage.

\section{Constraints to ICT Adoption among SMEs}

The acceptance and implementation of ICT in businesses have not had the same outcome for all businesses. Not all small to medium business owners or microbusinesses have taken up ICT nor do they intend on doing so in the near future (Ramsey, Ibbotson, Bell, \& Gray, 2003).

SMEs face numerous barriers and obstacles that complicate the adoption of ICT. Successful ICT adoption and implementation rely on both socioeconomic and technological issues; these issues can be based on internal or/and external factors (Arendt, 2008; Modimogale, 2008; MacGregor, Vrazalic, Carlsson, Bunker, \& Magnusson, 2002).

Walchzuch et al (2000) and Chitura et al (2008) categorised the barriers to ICT use into four broad categories. These include, firm awareness and access to infrastructure, confidence in the security framework, ICT use among business partners and adaptation of business processes (Chitura, Mupemhi, Dube, \& Bolongkikit, 2008b; Walczuch, Van Braven, \& Lundgren, 2000). The "Manager-Owner factors" category is a recent addition to the list, coming about as organisational and manager-owner factors are recognised as influencing ICT usage in small businesses (Wagner, Fillis, \& Johansson, 2003) .

MacGregor et al. (2002) argued that some of the barriers to ICT adoption are unique to SMEs, and came up with the following list: low level of existing hardware technology, the need to see immediate returns on investment (ROI), whereas E-commerce/ICT is a long term investment resistance to change, preference for traditional technologies such

as normal telephone system or face to face interaction, lack of IT skills and technical knowledge amongst employees, time constraints, lack of awareness about ICTs' 
business benefits, security concerns and finally, lack of ICT adoption among business partners. (MacGregor et al., 2002)

Walchzuch et al (2000) also consolidated a list of barriers SMEs face during ICT adoption, into three categories: awareness of SMEs and access to infrastructure, confidence in the security framework and ICT use among business partners and adaptation of business processes.

\section{South African SMEs}

South Africa is a developing country going through a growth period where exploiting different technologies holds huge benefits for the country. SMEs have the ability to obtain a large advantage through using emerging ICT technologies, such as internet and mobility (Balocco, Mogre, \& Toletti, 2009). To use an example, the emerging technology of VoIP is taking advantage of the converging markets of business. South African SMEs are thought to gain advantage through the potential use of mobile technologies. This is because a large proportion of the population has cell phones, which provides an excellent means of information sharing (Vosloo et al., 2005).

Infrastructures that allow voice and data to merge are readily available, with Skype currently the most popular of these applications. SMEs and other business types are starting to use these tools to communicate with clients and with each other. On the contrary, even though these technologies are available, $90 \%$ of businesses still use the conventional telephone systems. This slow uptake does not encourage the use of more advanced technologies (Vosloo et al., 2005).

The biggest problem in South Africa is the expensive connectivity costs coupled with a lack in infrastructure which supports emerging technologies. South Africa has been developed in a disparate way, where the urban areas have high end technologies whilst the rural areas remain underdeveloped and lacking basic infrastructures such as electricity and telephone lines, resources needed to succeed in a knowledge economy. The South African Government is aware of the necessity to partake in the global knowledge economy. Therefore, it has called for Telkom, until recently the monopolist fixed telephone line infrastructure provider, to reach South Africa's target by ensuring that the country is a connected one while at the same time reducing the cost of communication.

\section{Research Methodology}

The research was positivist in nature. An exploratory approach was used as our research investigated and provided indepth information in areas which have not been widely scrutinized. Both qualitative and quantitative research methods were used. Qualitative research was conducted to gain a more detailed understanding of the extent of use of ICTs and their perceived value. Alternatively, the quantitative research looked at the statistical significance of the barriers and opportunities faced by South African SMEs. Our research was cross sectional due to time constraints.

A questionnaire covering the key research questions was drawn up:

- What ICTs are used by SMEs?

- What are the barriers to ICT adoption experienced by SMEs?

- What is the value obtained from ICTs use by SMEs?

The research questionnaire is available on request from the authors. The research made use of a purposeful as well as a stratified sampling. For the purposeful sampling, specific groups of SMEs were selected from three industries which were identified as unique. These included services, production and retail. The SMEs were located both rurally and in urban areas. The stratified selection of SMEs was done in a random manner. In total, 300 questionnaires were sent out but only 33 useful responses were received, resulting in a response rate of $11 \%$.

We used an informal approach to conduct the interviews and two series of questions were asked. The first section focused on semi-structured questions, followed by queries which encouraged storytelling 
ethos. These questions were predominantly open-ended to encourage discussions. The focus of the interviews was on both SMEs and ICT providers. The results obtained from the interviews were then compared and contrasted to the findings of the questionnaires in order to analyse, whether or not, a correlation between the two existed.

\section{South African SMEs and ICT Use}

The primary objective was to find out which ICTs are used the mostly within SMEs and to what extent SMEs in South Africa are making use of ICT. From the literature, we found that SMEs do tend not to invest into more advanced technologies, when compared to larger organisations
(Vosloo et al., 2005). In order to investigate ICT usage within SMEs, the first hypothesis to be tested was based on the literature. An assumption was made that most SMEs adopt General ICT technologies, as compared to more advanced ICT technologies. The hypothesis was thus:

$H_{1}$ : Most SME's use general ICTs and relatively few use advanced ICTS.

In order to distinguish between different types of use and to test the hypothesis, ICT usage was categorised into three subsections of use namely; General ICT technology usage, Production-Orientated ICT technology usage and Advanced ICT technology usage. Figure 1 summarises the use of selected ICTs by SMEs.

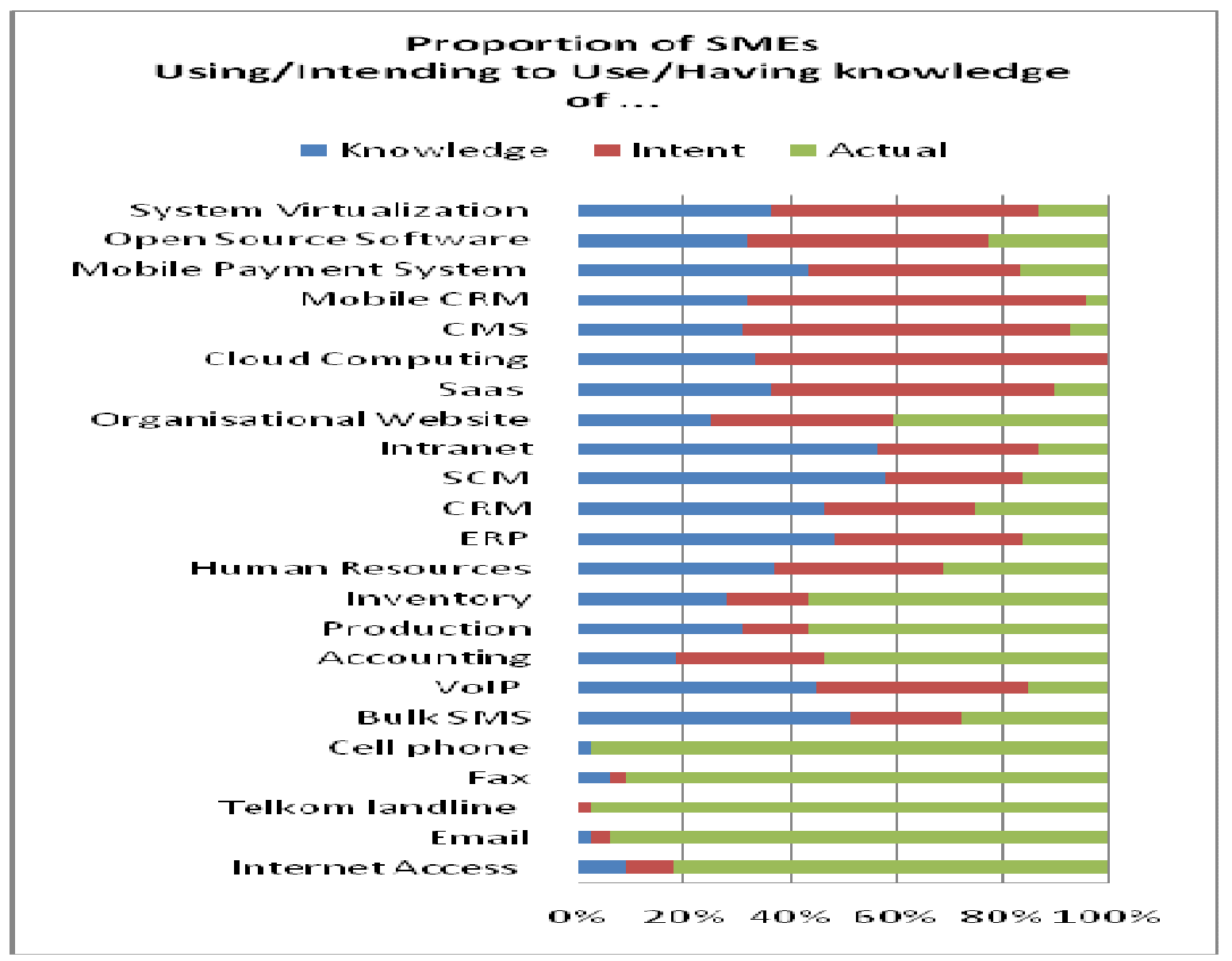

Figure 1: Extent of ICT Use in SMEs

The general use ICTs consisted of the following technologies: Internet access, Email, bulk SMS, VoIP, organisational website and intranet. The findings showed that $80.8 \%$ of the SMEs in the sample have internet access, $96.2 \%$ of them use email, 
23.1\% use bulk SMS, $19.2 \%$ use VoIP, $17.4 \%$ have intranet and $48 \%$ have an organisation website.

The production-orientated SMEs include ICTs such as, Accounting packages (52\%), Production packages (60\%), Inventory packages (64\%), Human Resource packages (36\%), Enterprise Resource Planning systems (ERP) (20.8\%), Customer Relationship Management applications (CRM) (32\%) and Supply Chain Management (SCM) Systems (16.7\%).

The advanced ICT SMEs use systems such as: Software as a Service (SaaS) (12.5\%), cloud computing (0\%), Content Management System (CMS) (8.7\%), mobile CRM (4.5\%), mobile payment system (17.4\%) and system virtualisation (16.7\%).

Of the general ICT users, not many SMEs had adopted VoIP, but there was a positive $42.3 \%$ who intended to implement it and $38.5 \%$ had knowledge of VoIP. Bulk SMS was only being used by $23.1 \%$ of the respondents, while $50 \%$ had knowledge on it and a fewer number of respondents intended to implement it. Firms with intranet capabilities were very low, with a usage of $17.4 \%$ and $52.2 \%$ had knowledge of it. Most SMEs had internet access, email services and a telephone and fax line.

The production ICT users had a high usage in Production packages, with 60\% using them and $16 \%$ intending to, Inventory packages had a 64\% usage and Accounting systems were used by $52 \%$ of the SMEs in the sample. The ERPs usage was not that prevalent with only $20.83 \%$ making use of them, but $41.7 \%$ of respondents stated that they intend to implement it. Only $16.7 \%$ of the respondents were making use of Supply Chain Management systems with a promising 33.3\% intending to adopt it.

Advanced ICT users were mostly using Mobile Payment systems and System Virtualisation, with $34.8 \%$ and $41.7 \%$ of the SMEs respectively intending to adopt these technologies. None of the SMEs were making use of cloud computing, although $61.9 \%$ of the respondents intend to adopt it.

From the findings, it was clear that the sample consisted mainly of General use ICT users, followed by Production-orientated ICT users and very few SMEs were using Advanced ICTs. Thus $\mathrm{H}_{1}$ is supported.

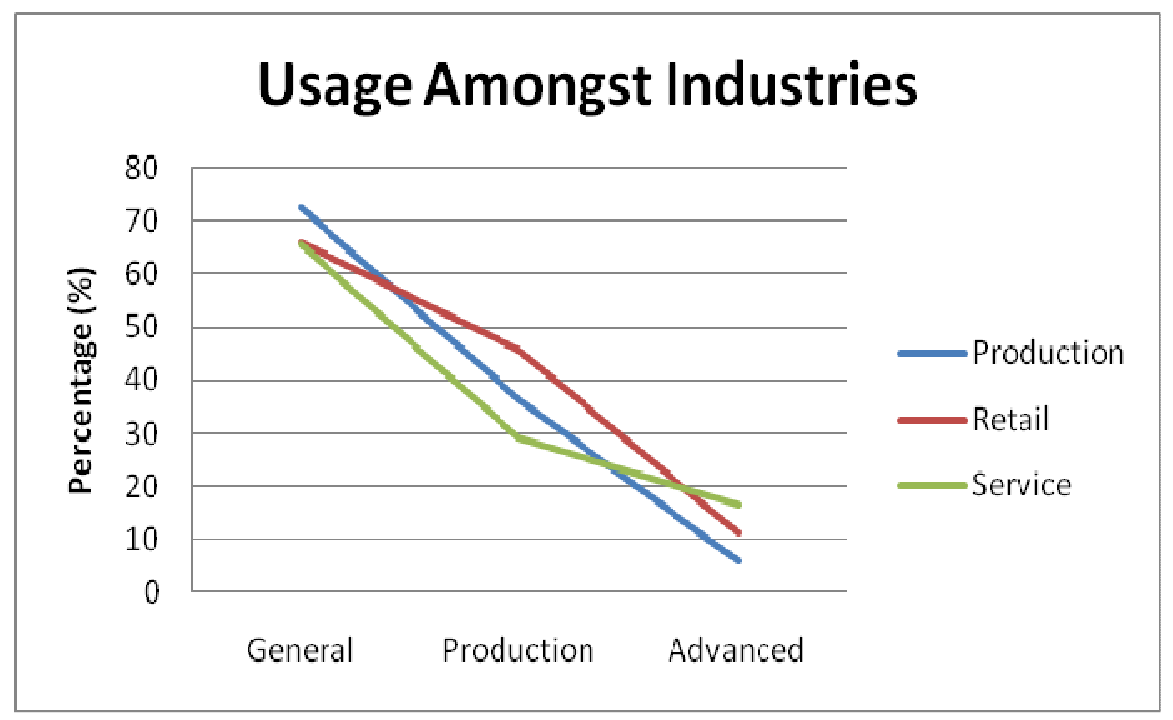

Figure 2: Usage Profiles Differences amongst Industries

There was a slight indication that the usage between the three industries in the sample differs, as shown in figure 2. It appears that the Production industry uses the most general ICT technologies and the least advanced ICT technologies. The Services 
industry seemed to have invested the most out of the three in Advanced ICT technologies and the Retail industry the most in Production-Orientated ICT technologies. However, these results are not fully conclusive since there were more production and retail SMEs in the sample than service SMEs.

\section{Barriers to ICT adoption}

The second component of the research investigated into the nature of the barriers experienced with regard to ICT adoption and use within South African SMEs. More specifically, the research intended to look into the perceived barriers for use of ICTs and whether or not South African SMEs experience critical barriers to adoption and usage. The hypothesis was that:

\section{$\mathrm{H}_{2}$ : South African SMEs experience critical barriers when using ICTs.}

A weighted average mean score $(1=$ Strongly Disagree; 3 = Neutral; 5 = Strongly Agree) was calculated for all the perceived barriers to ICT use, as found in the literature, and is depicted in table 1 below. Based on the weighted average score, the key critical barriers to ICT adoption were "Lack of awareness of the benefits of ICT adoption and use" followed by "Low employee skill level". The least significant barriers were the "Lack of Access to ICT infrastructures" and "Resistance to change within the organisation" barriers.

Table 1: Perceived Critical Barriers to ICT Adoption

\begin{tabular}{|l|c|c|c|c|c|c|}
\hline $\begin{array}{l}\text { Perceived Barrier (SD = Strongly Disagree; } \\
\text { N = Neutral; SA = Strongly Agree) }\end{array}$ & SD & D & A & SA & $\begin{array}{l}\text { Weighte } \\
\text { d } \\
\text { Average }\end{array}$ \\
\hline Lack of awareness about the benefits of ICT & 2 & 7 & 6 & 9 & 9 & $\mathbf{3 . 4 8}$ \\
\hline Employees IT skill level is too low & 3 & 6 & 8 & 12 & 4 & $\mathbf{3 . 2 4}$ \\
\hline $\begin{array}{l}\text { Employees satisfaction with traditional } \\
\text { technologies }\end{array}$ & 4 & 6 & 5 & 16 & 2 & $\mathbf{3 . 1 8}$ \\
\hline Security concerns & 2 & 8 & 7 & 15 & 1 & $\mathbf{3 . 1 5}$ \\
\hline ICTs too expensive & 1 & 9 & 9 & 13 & 1 & $\mathbf{3 . 1 2}$ \\
\hline $\begin{array}{l}\text { No sources of reliable and vendor-independent } \\
\text { information }\end{array}$ & 2 & 5 & 14 & 4 & 3 & $\mathbf{3 . 0 4}$ \\
\hline Time constraints & 2 & 7 & 12 & 12 & 0 & $\mathbf{3 . 0 3}$ \\
\hline $\begin{array}{l}\text { ICT applications are not tailored to the way SMEs } \\
\text { do business }\end{array}$ & 2 & 8 & 11 & 11 & 1 & $\mathbf{3 . 0 3}$ \\
\hline $\begin{array}{l}\text { Business partners, suppliers and customers do } \\
\text { not make use of ICT }\end{array}$ & 3 & 12 & 6 & 9 & 3 & $\mathbf{2 . 9 1}$ \\
\hline $\begin{array}{l}\text { Low level of existing hardware technology in } \\
\text { place }\end{array}$ & 2 & 8 & 13 & 5 & 2 & $\mathbf{2 . 9 1}$ \\
\hline Unreliable service providers & 1 & 14 & 8 & 9 & 1 & $\mathbf{2 . 8 4}$ \\
\hline $\begin{array}{l}\text { Organisation required immediate ROI, ICT } \\
\text { implementation would not deliver this result }\end{array}$ & 2 & 9 & 16 & 6 & 0 & $\mathbf{2 . 7 9}$ \\
\hline Resistance to change within our organisation & 3 & 13 & 6 & 11 & 0 & $\mathbf{2 . 7 6}$ \\
\hline $\begin{array}{l}\text { No access to ICT infrastructures (e.g. electricity, } \\
\text { telephone lines etc) }\end{array}$ & 9 & 14 & 6 & 3 & 1 & $\mathbf{2 . 1 8}$ \\
\hline
\end{tabular}

The above findings suggest that SMEs in South Africa experience critical barriers to ICT adoption and use. The outcome from a number of follow-up interviews with SME owners in the sample revealed similar results, confirming the findings of the questionnaires. Most SME owners rated lack of awareness as the key barrier to ICT 
adoption. Coupled with this, they all found another major barrier to be that there are no vendors who cater for SMEs. The lack of knowledge of SME owners is not only with regards to the technologies available for use today, but also knowledge on who can supply them with ICT services. Examples used were: lack of knowledge on where to go for a customised system for their enterprise and where they can buy an off the shelf package and which ones they should buy, as they do not know which packages are most suited to their needs. Even though "reliable sources of vendor independent information" did not appear to be a major barrier in the questionnaire responses, the interviews revealed it to be a much bigger barrier. The reason for this could be that the SME owners filling out the questionnaire did not understand what the question meant, but when asked about it in layman's terms they immediately understood and recognized it to be a strong attributing fact as to why they have not adopted or invested heavily in ICT.

SME owners also think that ICTs are too expensive to invest in and will cost more than the value they might add, and most of them showed a lack of understanding of the benefits that result from use of ICTs. Another factor that was revealed in the interviews with the SMEs was that of "after sales service". Beside the fact that SME owners did not know who to consult for help and the fact that SME owners are of the belief that consultants cater more for larger organizations than small, SME owners that have implemented ICT in their organization said that the after sales service of the product was poor. After product roll out in the enterprise, the consultants that were initially involved in the roll out of the system not available for further support and the SME owners, many of whom do not have comprehensive knowledge on ICT, were left on their own with a system they did not know how to use properly and one that does not cater fully to their needs.

An overall lack of awareness therefore, seems to exist amongst SME owners in South Africa with respect to the availability of ICTs which they can possibly use; knowledge on their respective benefits; as well as knowledge as to who to turn to for help with regards to both systems analysis and the design and building of an actual system for their needs.

\section{Value Added through ICT Adoption}

The third aspect of the research looked into the value added through ICT use within SMEs in South Africa. The hypothesis assumed that using ICT in an organisation adds value to that organisation. The hypothesis was formulated as such:

\section{$H_{3}:$ ICTs are perceived by SMEs to add value to their business}

Table 2 summarises and ranks the perceived value added through ICT adoption. The key perceived benefits experienced by SME owners focus on customer-centric improvements: increase in customer satisfaction, faster turnaround time, better quality of service and improved marketability. However, some operational benefits are also noted: more efficient and effective business processes. Interestingly, employee-centred benefits and financial impacts appear not to be major benefits from ICT adoption. 
Table 2: Perceived Value through ICT Adoption

\begin{tabular}{|c|c|c|c|c|c|c|}
\hline Value Added & SD & $\mathrm{D}$ & $\mathrm{N}$ & A & SA & $\begin{array}{l}\text { Weighted } \\
\text { Average }\end{array}$ \\
\hline Customer satisfaction has increased & 0 & 0 & 4 & 12 & 9 & 4.20 \\
\hline $\begin{array}{l}\text { Our quality of service has improved due to } \\
\text { ICT }\end{array}$ & 0 & 1 & 3 & 13 & 9 & 4.15 \\
\hline Turnaround time has improved & 0 & 0 & 3 & 16 & 7 & 4.15 \\
\hline $\begin{array}{l}\text { Business processes are more efficient, tasks } \\
\text { are performed more quickly }\end{array}$ & 0 & 1 & 2 & 16 & 7 & 4.12 \\
\hline $\begin{array}{l}\text { The organisation has become more } \\
\text { marketable }\end{array}$ & 0 & 1 & 3 & 15 & 7 & 4.08 \\
\hline $\begin{array}{l}\text { The organisation has become more effective } \\
\text { since the adoption of ICT }\end{array}$ & 0 & 1 & 3 & 16 & 6 & 4.04 \\
\hline $\begin{array}{l}\text { I have experienced increased efficiency of } \\
\text { tasks since ICT implementation }\end{array}$ & 0 & 1 & 3 & 16 & 6 & 4.04 \\
\hline Short term targets are more achievable & 0 & 0 & 6 & 14 & 6 & 4.00 \\
\hline Scheduling has become more efficient & 0 & 0 & 7 & 16 & 3 & 3.85 \\
\hline Organisation has become more profitable & 0 & 0 & 9 & 12 & 5 & 3.85 \\
\hline Stock levels are always up to date & 0 & 0 & 9 & 11 & 5 & 3.84 \\
\hline $\begin{array}{l}\text { Communication within the organisation has } \\
\text { improved }\end{array}$ & 0 & 1 & 8 & 12 & 5 & 3.81 \\
\hline $\begin{array}{l}\text { Organisational goals are being met with } \\
\text { more ease }\end{array}$ & 0 & 0 & 9 & 13 & 4 & 3.81 \\
\hline $\begin{array}{l}\text { Employees are able to work from remote } \\
\text { locations }\end{array}$ & 0 & 1 & 8 & 14 & 3 & 3.73 \\
\hline Staff morale has increased & 0 & 0 & 10 & 13 & 3 & 3.73 \\
\hline Product quality has been improved & 0 & 1 & 10 & 10 & 5 & 3.73 \\
\hline $\begin{array}{l}\text { Relationships with suppliers have been } \\
\text { improved }\end{array}$ & 0 & 0 & 10 & 13 & 3 & 3.73 \\
\hline Customer base has increased & 0 & 1 & 10 & 11 & 4 & 3.69 \\
\hline Increased revenue since implementation & 0 & 3 & 9 & 11 & 3 & 3.54 \\
\hline $\begin{array}{l}\text { Operational costs have decreased since the } \\
\text { ICT has been adopted }\end{array}$ & 1 & 1 & 9 & 15 & 0 & 3.46 \\
\hline
\end{tabular}

The interviews confirmed these findings. Despite the fact that most SMEs only engage in General ICT technologies as opposed to Production-Orientated and Advanced technologies, SME owners still feel that investing in ICT can add considerable value to their enterprises. The interviews reveal that most SME owners who have adopted ICT feel their organisation has turned out to be more marketable and they have been able to increase their customer base as a result. SME owners who do not have an organisational website still believe that the internet is a good medium for them to advertise their business through websites such as Gumtree and this can potentially increase their customer base. They also point out that adoption of ICTS has brought positive changes in their business processes and their operations are now more efficient and effective, resulting in improved customer satisfaction. However, some SME owners believe that the investment in ICT has been substantial and there has been no noticeable increase in revenue despite the more efficient business processes. This observation further validates the findings of MacGregor et al (2002) who argued that SMEs need to see the immediate returns on investment (ROI), whereas ICT is a long term investment. 
The final section of this research investigates whether there is a relationship of the barriers to ICT adoption and the value gained from using ICT within an SME. We used a Spearman Rank Order Correlation test to identify whether or not any relationship exists. The findings illustrate 6 significant correlations between some of investigated barriers to ICT and value propositions. Table 3 below depicts the results.

\section{Table 3: Relationship between ICT Barriers and Value}

\begin{tabular}{|c|c|c|c|c|c|}
\hline \multirow{2}{*}{\multicolumn{2}{|c|}{ Pair of Variables }} & \multicolumn{4}{|c|}{$\begin{array}{l}\text { Spearman Rank Order Correlations (Adop } \\
\text { MD pairwise deleted } \\
\text { Marked correlations are significant at } \mathrm{p}<\end{array}$} \\
\hline & & $\begin{array}{c}\text { Valid } \\
\mathrm{N}\end{array}$ & $\begin{array}{c}\text { Spearman } \\
R\end{array}$ & $t(N-2)$ & p-value \\
\hline VQ1 & $\& B Q 1$ & 33 & -0.184529 & -1.04536 & 0.303938 \\
\hline VQ1 & $\& \mathrm{BQ5}$ & 33 & -0.141944 & -0.79839 & 0.430717 \\
\hline VQ1 & \& BQ6 & 3 & -0.289664 & -1.6 & 2027 \\
\hline VQ1 & $\& B Q 8$ & 3 & O. 0 & 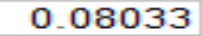 & 38 \\
\hline VQ1 & \& BQ14 & 3 & 0.05 & 0.2 & 40 \\
\hline VQ3 & \& BQ1 & 3 & -0.50 & -3.23 & .002875 \\
\hline VQ3 & \& BQ5 & 33 & -0.49 & -3.16267 & 0.003487 \\
\hline VQ3 & \& BQ6 & 33 & -0.50 & -3.24178 & 0.002838 \\
\hline VQ3 & \& BQ8 & 33 & -0.41 & -2.54930 & 0.015961 \\
\hline VQ3 & \& BQ14 & 33 & -0.24 & -1.3 & 0.174860 \\
\hline VQ7 & $\& B Q 1$ & 3 & -0.2 & -1.31 & o. 196727 \\
\hline VQ7 & \& BQ5 & 3 & -0.0 & -0.55077 & 0.585741 \\
\hline VQ7 & \& BQ6 & 33 & -0.0 & -0.07 & 0.944081 \\
\hline VQ7 & \& BQ8 & 3 & -0.3 & -1.78 & O. 0 \\
\hline VQ7 & \& $B Q 14$ & 33 & -0.3 & $-1 . \varsigma$ & $\mathrm{O}_{-} \mathrm{C}$ \\
\hline VQ8 & $\&$ & & -0.3 & -1 & 57997 \\
\hline VQB & \& BQ5 & & -0.1 & -0.6 & 0.551393 \\
\hline VQ8 & $\& B Q 6$ & & O. 0 & 491 & .838982 \\
\hline VQB & \& BQ8 & & -0.0 & -0.4 & 8919 \\
\hline VQB & \& BQ14 & 3 & -0.076380 & -0.4 & .672684 \\
\hline VQ10 & \& BQ1 & 3 & -0.497764 & -3.19 & .003203 \\
\hline VQ10 & \& BQ5 & 33 & -0.129758 & -0.72 & .471701 \\
\hline VQ10 & \& BQ6 & 33 & -0.072551 & -0.40501 & 0.688249 \\
\hline VQ10 & $\& B Q 8$ & 33 & -0.307252 & -1.79766 & 0.081978 \\
\hline VQ10 & \& BQ14 & 33 & -0.382295 & -2.30350 & 0.028121 \\
\hline
\end{tabular}

Two value propositions namely quality of service (VQ1) and turnaround time (VQ10) are impacted by the barriers to ICT. Lack of employee IT skills (BQ1), resistance to change (BQ5), lack of awareness (BQ6) and employee satisfaction with traditional technologies (BQ8) adversely impact the quality of service in SMEs whilst turnaround time is negatively impacted by both unreliable vendor information (BQ14) and lack of employee IT skills (BQ1).

It is interesting to note that lack of employee IT skills (BQ1), lack of awareness (BQ6) and employee satisfaction with traditional technologies (BQ8) are the three most prominent barriers to ICT adoption whilst service quality and turnaround time are $2^{\text {nd }}$ and $3^{\text {rd }}$ most important benefits of ICT adoption as perceived by SMEs.

\section{Conclusion}

This research looked at the role that ICT plays within SMEs in South Africa and in particular, it looked at using ICTs to add value to SMEs. Additionally, the critical barriers experienced by SMEs were also queried.

The research conducted revealed that SMEs in South Africa are currently investing mainly in General use ICT technologies, mainly due to the fact that SME owners lack knowledge and awareness of the various technologies available for use, as well as the benefits to be gained from their use. 
Even though SME owners are mainly adopting General use ICTs and prefer traditional methods of doing business, as opposed to new computerised methods, they still perceive ICT adoption as beneficial and use it to add value to their enterprises. The research therefore, confirmed that ICT use in an enterprise definitely does add value to the SME, with the highest rated value added being those of ICT helping the SMEs to improve their customer satisfaction levels, as well as improving their levels of service, which also affect the customer.

The research further revealed the fact that South African SMEs experience critical barriers to ICT use within their enterprise. It was proven that the barriers to ICT do not only affect the adoption and use thereof, but also have a negative effect on the value that could be gained from otherwise adopting ICT. The most prevalent barriers included the fact that SME owners had an overall lack of understanding with regards to ICT. Many SME owners also thought of ICT as a greater expense to the enterprise as compared to its added the value. An overall lack of understanding as to the benefits of ICT is evident amongst the SMEs sampled in this research paper.

It would be interesting to see the results of this study on a larger sample, encompassing more industries and regions within South Africa. Many of the SMEs in the sample showed an intent to adopt and use more advanced ICTs in the near future.

\section{References}

Arendt, L. (2008). "Barriers to ICT Adoption in Smes: How to Bridge the Digital Divide?," Journal of Systems and Information Technology, 10 (2), 93-108.

Bacon, N. \& Hoque, K. (2005). "HRM in the SME Sector: Valuable Employees and Coercive Networks," The International Journal of Human Resource Management, 16(11), 1976-1999.

Balocco, R., Mogre, R. \& Toletti, G. (2009). "Mobile Internet and SMEs: A Focus on the
Adoption," Industrial Management \& Data Systems, 109 (2), 245-261.

Carr, N. G. (2004). IT Doesn't Matter. IEEE Engineering Management Review, 32 (1), 24 -32 .

Chitura, T., Mupemhi, S., Dube, T. \& Bolongkikit, J. (2008b). "Barriers to Electronic Commerce Adoption in Small and Medium Enterprises: A Critical Literature Review," Journal of Internet Banking and Commerce, 13 (2), 1-13.

Hoffman, N. P. (2000). "An Examination of the Sustainable Competitive Advantage Concept: Past, Present and Future," Academy of Marketing Science Review, 4, 116.

Jentzsch, R. \& Miniotas, A. (1999). "The Application of E-Commerce to a SME," Proceedings of the 10th Australasian Conference on Information Systems, December 1999, Wellington, New Zealand, 435-447.

Locke, S. (2004). "ICT Adoption and SME Growth in New Zealand," Journal of American Academy of Business, 4 (1/2), 93102.

MacGregor, R., Vrazalic, L., Carlsson, S., Bunker, D. \& Magnusson, M. (2002). "The Impact of Business Size and Business Type on Small Business Investment in Electronic Commerce: A Study of Swedish Small Businesses," Australian Journal of Information Systems, 9 (2), 31-39.

Modimogale, L. \& Kroeze, J. (2009). "Using ICTs to Become a Competitive SME in South Africa," Proceedings of the 13th International Business Information Management Association (IBIMA), November 2009, Marrakech, Morocco, p 504-513.

Peppard, J. \& Ward, J. (2004). "Beyond Strategic Information Systems: Towards an IS Capability," Journal of Strategic Information Systems, 13(2), 167-194.

Porter, M. E. (2001). "Strategy and the 
Internet," Harvard Business Review, 79 (3), 62-79.

Porter, M. E. \& Millar, V. E. (1985). "How Information Gives You Competitive Advantage," Harvard Business Review, 63 (4), 149-160.

Ramsey, E., Ibbotson, P., Bell, J. \& Gray, B. (2003). "E-opportunities of Service Sector SMEs: An Irish Cross-Border Study," Journal of Small Business and Enterprise Development, 10 (3), 250-264.

Taylor, M. \& Murphy, A. (2004). "SMEs and E-Business," Journal of Small Business and Enterprise Development, 11 (3), 280-289.

Vosloo, S., Van Belle, J. P. (2005). "Egovernment and the E-readiness of NonProfit Organisations in the Western Cape," South Africa. 2nd Annual Conference of the Community Informatics Research Network (CIRN),August 2005, Cape Town, South Africa, 24-26.

Vrazalic, L., Stern, D., MacGregor, R., Carlsson, S. \& Magnusson, M. (2003). "Barriers to E-Commerce Adoption in Smes: Underlying Factors from a Swedish Study," Proceedings of the 14th Australasian Conference on Information Systems (ACIS), July 2003, Perth, Australia.

Walczuch, R., Van Braven, G. \& Lundgren, H. (2000). "Internet Adoption Barriers for Small Firms in the Netherlands," European Management Journal, 18 (5), 561-572. 